Z. Zhang* and Z. J. Tan

\title{
A Multi Scale Strategy for Simulation of Microstructural Evolutions in Friction Stir Welding of Duplex Titanium Alloy
}

https://doi.org/10.1515/htmp-2018-0148

Received September 05, 2018; accepted October 30, 2018

\section{Introduction}

Friction Stir Welding (FSW) has been invented for more than two decades and quickly applied to automobile, ship, high speed train, aeronautics and astronautics industries [1-4]. FSW can be suitable for joining aluminum alloys [5-9], magnesium alloys [10-12], titanium alloys [13-15], steels [16-18]. For the cited industries, the joint of polymer/metal is important as reported [19-21]. The design on the welding parameters can greatly improve the welding quality of the friction stir welds [22-25].

The welding temperature in FSW is lower than the melting point $\left(T_{\mathrm{m}}\right)$ but higher than the temperature for recrystallization $[26,27]$. The heat in FSW is generated by two parts: the frictional and the plastic dissipations [28-30]. The temperature variations in FSW process have been widely studied in different models. Nandan et al. [31] proposed Computational Fluid Dynamic (CFD) based model to simulate the material flows and the heat generations in FSW of steel. Eulerian mesh is used to avoid possible mesh entanglements in this simulation. Sticking contact or sliding contact with consideration of shear failure criterion can be used for the determination of the material velocities on the contact surfaces [32, 33] in CFD models. Schmidt et al. [34] proposed a fully coupled thermo-mechanical model in which Arbitrary Lagrangian and Eulerian technique is used for the controlling of the excessive mesh distortions. The material flow patterns and the dissipated powers by both friction and plastic deformation can be then determined. Based on the energy dissipations, Zhang et al. [29] found that the FSW for joining of thin plates is much more efficient in energy. Adaptive re-meshing technique can be also used for simulation of FSW process based on solid mechanics. Buffa et al. [35] proposed a finite element model with adaptive re-meshing technique to compare the conical pin with the cylindrical pin in FSW. Zhang et al. [36] proposed a thermo-mechanical model for prediction of the heat generations and the induced macroscopic and microscopic residual stresses evolutions in

FSW. The temperatures and the material deformations in
*Corresponding author: Z. Zhang, State Key Laboratory of Structural Analysis for Industrial Equipment, Department of Engineering Mechanics, Faculty of Vehicle Engineering and Mechanics, Dalian University of Technology, Dalian 116024, China; International Research Center for Computational Mechanics, Dalian University of Technology, Dalian, 116024, China, E-mail: zhangz@dlut.edu.cn Z. J. Tan, State Key Laboratory of Structural Analysis for Industrial Equipment, Department of Engineering Mechanics, Faculty of Vehicle Engineering and Mechanics, Dalian University of Technology, Dalian 116024, China 
FSW are widely investigated by different numerical and analytical models [37-41].

The determination of heat sources and material deformations in FSW provides the possibility for further investigations on the microstructural evolutions. Microstructural evolution plays the key role for the determination of the friction stir weld quality. The numerical method and the systematic theories for the controlling of microstructural evolutions are essential for the development of the FSW technique. ZenerHollomon parameter can be used to evaluate the grain sizes in FSW of aluminum alloy [42-45]. Cellular automata [45, 46] and Monte Carlo models [47, 48] can be used to simulate the recrystallization and the grain growth in FSW. Evolution of the precipitated phases can be further included in Monte Carlo model to investigate the pining effects [49]. Monte Carlo model, as well as cellular automata model, has been verified to be successful for simulation of the formation of equiaxed grains in the stirring zone and the coarsening of the grains in the heat affected zone in FSW of aluminum alloys. But for duplex titanium alloy $(\alpha+\beta)$, the equiaxed grain can be formed only when the cooling rate is very low [50]. When the cooling rate becomes higher, as revealed in FSW, acicular grain for $\alpha$ phase can be formed. It is necessary to develop new numerical model to accurately describe the mechanism on the microstructural evolutions in FSW of duplex titanium alloy. So, a new Monte Carlo model, which consists of the grain growth model in grain cluster scale and the phase transformation model in one grain scale, is proposed in current work with combination of a successful adaptive re-meshing model to study the microstructural evolutions in FSW of Ti-6Al-4V. The effect of the welding parameters on the grain growths in different welding zones is further investigated.

\section{Finite element model}

Adaptive re-meshing model is used to simulate the FSW process, which can provide the necessary strain rates and temperature histories for the further simulation on the microstructural evolutions. The tool shoulder diameter is $10 \mathrm{~mm}$. The pin diameter is $2.5 \mathrm{~mm}$. The rotating speeds are changed from $800 \mathrm{rpm}$ to $1100 \mathrm{rpm}$. To ensure the success of the model, the translational velocity is selected to be $0.5 \mathrm{~mm} / \mathrm{s} \sim 0.8 \mathrm{~mm} / \mathrm{s}$. The welding parameters are summarized in Table 1. According to previous work [51], pre-heating is very important to
Table 1: Welding parameters for the simulated cases.

\begin{tabular}{lrr}
\hline Cases & $\begin{array}{r}\text { Transverse speed } \\
\boldsymbol{v}(\mathrm{mm} / \mathbf{s})\end{array}$ & $\begin{array}{r}\text { Rotational speed } \\
\boldsymbol{\omega}(\mathrm{rpm})\end{array}$ \\
\hline 1 & 0.5 & 1100 \\
2 & 0.8 & 1100 \\
3 & 0.5 & 800 \\
\hline
\end{tabular}

obtain weld without defects. So, a plunge stage is included for pre-heating of the local region around the welding tool. The plunging speed of the welding tool is $0.4 \mathrm{~mm} / \mathrm{s}$. The finite element model of FSW is shown in Figure 1. The initial element sizes are chosen to be $1.03 \mathrm{~mm}$ to $2.06 \mathrm{~mm}$. The selection of element size is according to previous work [52]. Adaptive re-meshing technique is used to control the mesh distortions and avoid mesh entanglements. The solutions to the temperatures and the displacements are mapped to the new generated meshes [53].

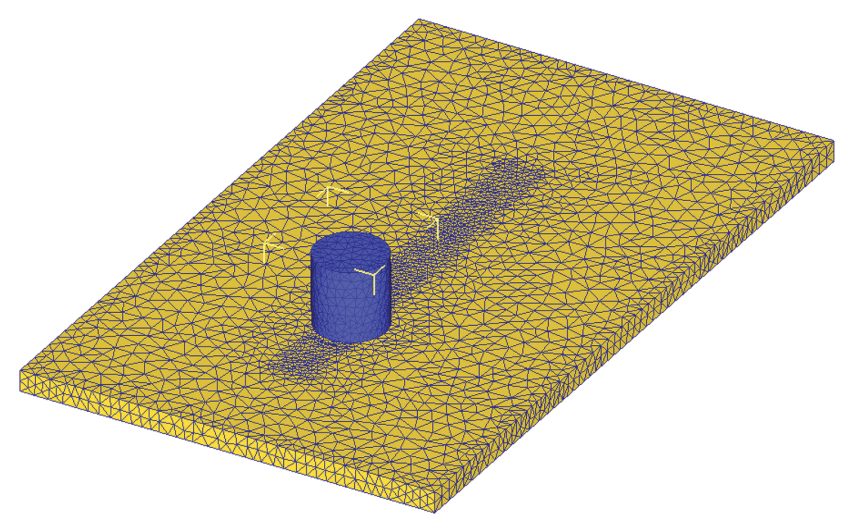

Figure 1: Finite element model.

At each step, the thermal and mechanical responses are computed,

$$
\begin{gathered}
{ }_{i} K_{i} \Delta U={ }_{i}^{n+1} F_{\operatorname{ext}}(t) \\
C_{\mathrm{T}} \stackrel{+}{T}+K_{\mathrm{T}} T=P_{\mathrm{T}}
\end{gathered}
$$

where $C_{\mathrm{T}}$ is the heat capacity matrix. $K_{\mathrm{T}}$ is the thermal conductivity matrix. $T$ is temperature. $P_{\mathrm{T}}$ is the heat flux vector. $K$ is the tangent stiffness matrix and $\Delta U$ is the incremental displacements. 
The transient heat conduction equation is solved by the finite difference method,

$$
T_{t+\Delta t}=T_{t}+\Delta t\left[(1-\beta) \dot{T}_{t}+\beta \dot{T}_{t+\Delta t}\right]
$$

where $\beta$ is the parameter controlling the convergence of time.

Tabulated flow stress is used as functions of strain rates and temperatures,

$$
\sigma_{y}=\sigma_{y}\left(\bar{\varepsilon}^{p}, \frac{\bullet p}{\bar{\varepsilon}}, T\right)
$$

where $\sigma_{\mathrm{s}}$ is the flow stress. $\bar{\varepsilon}^{p}$ is the equivalent plastic strain. $\dot{\bar{\varepsilon}}^{p}$ is the equivalent plastic strain rate. The curves for flow stress of Ti-6Al-4V are taken from the software database in Deform-3D and shown in Figure 2.

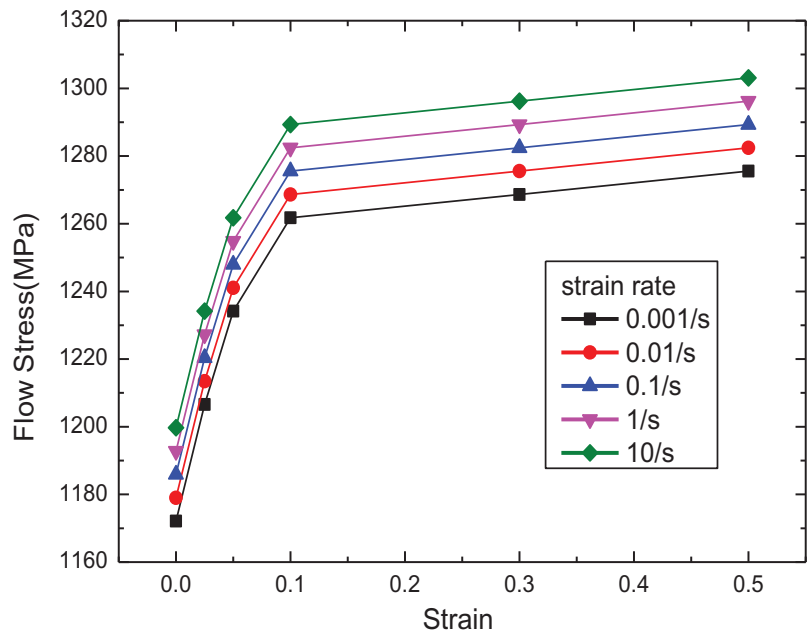

(a) $20^{\circ} \mathrm{C}$

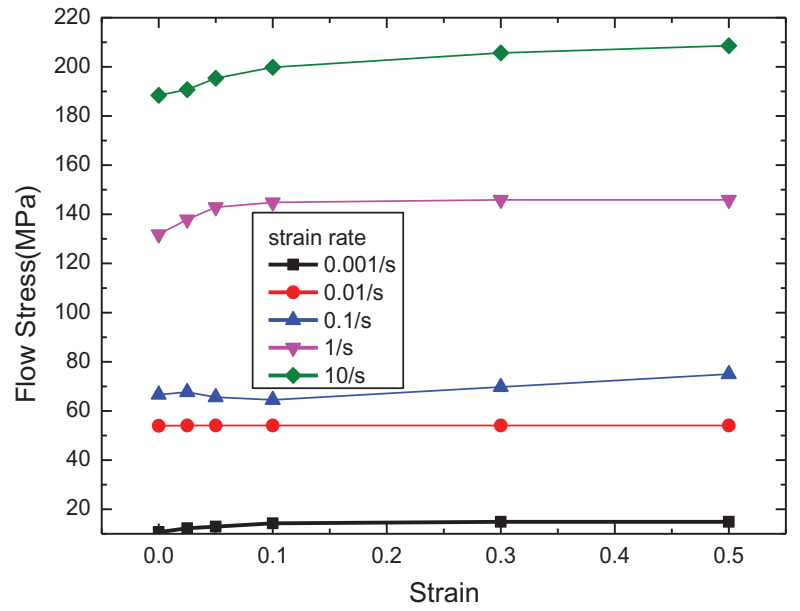

(c) $900^{\circ} \mathrm{C}$
The total energy in FSW includes the kinematic energy, internal energy and frictional energy in FSW [24],

$$
\begin{aligned}
E_{W}= & \int_{0}^{t} \iiint_{S} \tau \cdot \dot{\gamma} d S d t+\iiint_{V} \frac{1}{2} \rho \mathbf{v} \cdot \mathbf{v} d V \\
& +\left(\int_{0}^{t}\left(\int_{V} \sigma_{v}: \dot{\varepsilon} d V\right) d \tau+\int_{0}^{t}\left(\int_{V} \sigma_{c}: \dot{\varepsilon} d V\right) d \tau\right)
\end{aligned}
$$

where $\sigma_{c}$ is the stress without viscous dissipation effect. $\sigma_{v}$ is the viscous stress. $\dot{\varepsilon}$ is the strain rate. $v$ is the velocity vector. $\tau$ is the frictional stress. $\dot{\gamma}$ is the slipping velocity. $t$ is time. $\rho$ is density. $S$ is the contact surface. $V$ is the volume in the computational region.

Part of the frictional energy can be dissipated into heat,

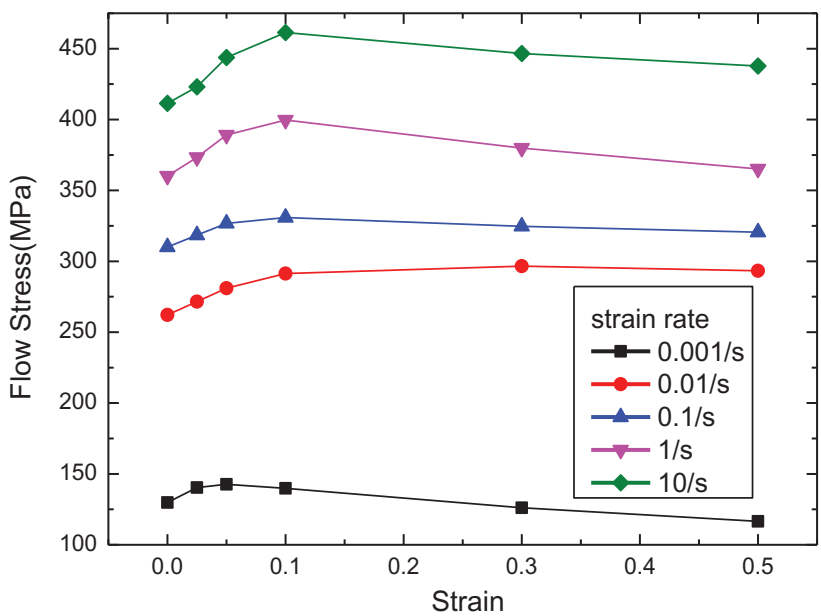

(b) $700^{\circ} \mathrm{C}$

Figure 2: Flow stress curves at different strain rates in different temperatures. 


$$
E_{f}=\delta \int_{0}^{t} \iint_{S} \tau \cdot \dot{\gamma} d S d t
$$

where $\delta$ is the coefficient and is selected to be 0.9 .

Part of the internal energy can be dissipated into heat,

$$
E_{i}=\eta\left(\int_{0}^{t}\left(\int_{\mathrm{V}} \sigma_{\mathrm{V}}: \dot{\varepsilon} d V\right) d \tau+\int_{0}^{t}\left(\int_{\mathrm{V}} \sigma_{\mathrm{c}}: \dot{\varepsilon} d V\right) d \tau\right)
$$

where $\eta$ is the coefficient and is selected to be 0.9 by default

Deform-3D is used for the simulation of the FSW process. The obtained temperature histories in different welding zones are used for further simulation on the microstructural evolutions in FSW of Ti-6Al-4V.

\section{Microstructural evolution model}

Different to the Monte Carlo model for FSW of microstructural changes in aluminum alloys used in previous works $[47,48]$, two phases including $\alpha$ and $\beta$ are considered in this new developed Monte Carlo model in grain cluster scale. In order to simulate the grain structure during the FSW process, a two-dimensional matrix with lattice points $N \times N$ is used. Each cell in the simulation consists of 1 to $q$ states and $q$ is selected to be 100. $m=8$ is the number of surrounding cells. The free energy is determined by the present crystallographic orientation and the neighborhood orientations at the randomly selected point. In this grain growth model, the energy of the system in the Monte-Carlo simulation is described as [47],

$$
E=-J \sum_{i=1}^{m}\left(\delta_{q_{i} q_{j}}-1\right)
$$

where $J$ is the lattice energy density. $\delta_{q_{i} q_{j}}$ is the Kronecker delta function.

The acceptance of the change of the crystallographic orientation is depending on the following Boltzmann probability equation [47],

$$
p=\left\{\begin{array}{cc}
1, & \Delta E \leq 0 \\
e^{\frac{\Delta E}{k_{B} T}}=e^{-\frac{\left(m_{2}-m_{1}\right) J}{k_{B} T}}, & \Delta E>0
\end{array}\right.
$$

where $\Delta E$ is the change of grain-boundary energy due to reorientation. $k_{\mathrm{B}}$ is the Boltzmann constant. $T$ is the temperature. $m_{1}$ and $m_{2}$ represent the numbers of different orientations before and after reorientation. If $\Delta E<0$, the random reorientation of this cell is acceptable. Otherwise, the reorientation conforms to Boltzmann probability.

The relationship between the simulated grain size $L$ and the Monte Carlo step can be obtained as [47],

$$
L=K_{1} l(M C S)^{n_{1}}
$$

where $l$ is the cell length in the Monte Carlo model. $K_{1}$ and $n_{1}$ are model constants. The computed relationship between $\log _{10} M C S$ and $\log _{10} L$ is shown in Figure 3 which is used to determine the constants $K_{1}$ and $n_{1}$.

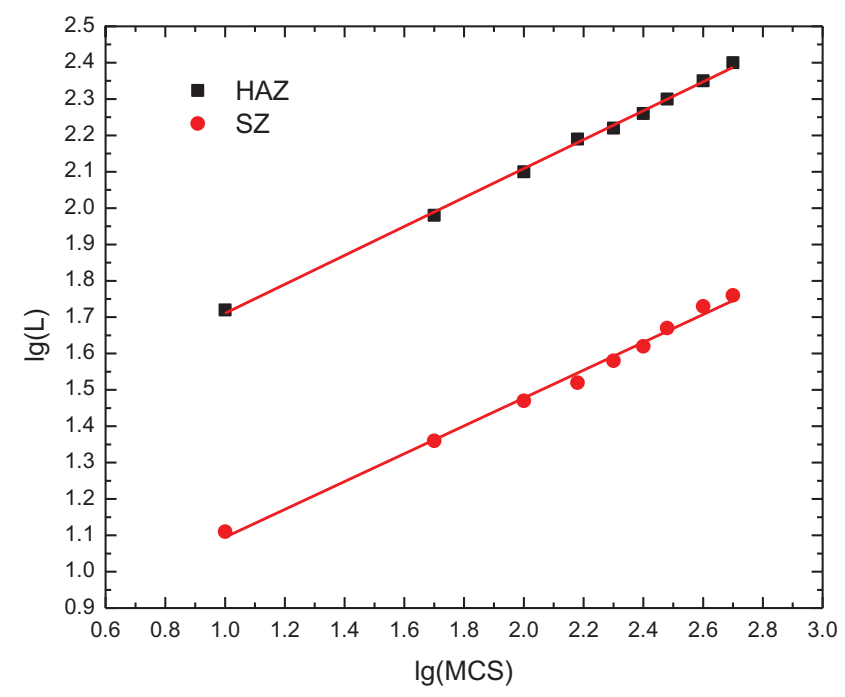

Figure 3: Relation between MCS and L in SZ and HAZ.

The grain growth phenomena in materials can be described by the following equation [54],

$$
L^{n}=L_{0}^{n}+k t \cdot \exp \left(-\frac{Q}{R T}\right)
$$

where $L_{O}$ is the initial grain size which is selected to be $40 \mathrm{~mm}$ according to Ref. [55]. $t$ is the heating and cooling time and $Q=251 \mathrm{~kJ} / \mathrm{mol}$ is the activation energy of Ti-6Al$4 \mathrm{~V}[55,56]$. The combination of eq. (10) and eq. (11) can lead to the relationship between the MCS and the time and temperature,

$$
M C S^{n n_{1}}=\left(\frac{L_{0}}{K_{1} l}\right)^{n}+\frac{k}{\left(K_{1} l\right)^{n}} \exp \left(-\frac{Q}{R T}\right) t
$$


where $k=2.02$ and $n=2.0$ are the proportional constants $[54,55] . R=8.31 \mathrm{~J} \cdot \mathrm{K} \cdot \mathrm{mol}^{-1}$ is the gas constant. $K_{1}$ and $n_{1}$ are the intercept and the slope in the Figure 3.

As a solid state joining technique, no melting occurs in the FSW process. But the temperature is still high enough for possible phase transformation from $\beta$ to $\alpha$ in the FSW of Ti- $6 \mathrm{Al}-4 \mathrm{~V}$. When the material is heated to be higher than $980^{\circ} \mathrm{C}$, only $\beta$ phase exists in the Stirring Zone (SZ). The nucleus of $\alpha$ phase is formed preferentially at $\beta$ grain boundaries and the phase transformation occurs during the cooling progress. The $\beta$ grain can grow along $<110\rangle$ crystallographic direction. So, a phase transformation model in one grain scale is newly established for the further investigations on the formation of the acicular $\alpha$ phase in the FSW process.

The phase transformation from $\beta$ to $\alpha$ needs new definition on nucleation rate. The nucleation rate of $\alpha$ phase on $\beta$ grain boundaries is given by [57],

$$
N=N_{v} \frac{k_{B} T}{h} \exp \left(-\frac{\Delta G_{m}}{k_{B} T}\right) \exp \left(-\frac{\Delta G_{C}^{*}}{k_{B} T}\right)
$$

where $h$ is the Planck constant. $N_{v}$ is the number of nucleation site per unit volume. $\Delta G_{m}$ is the activation energy for atomic migration across the interface. $\Delta G_{C}^{*}$ is the activation barrier for nucleation [57],

$$
\Delta G_{C}^{\star}=\frac{16 \pi \gamma_{\alpha \beta}^{3}}{3 \Delta g^{2}} S(\theta)
$$

where $\gamma_{\alpha \beta}$ is the free interface energy when the connect surface $S_{\alpha \beta}$ is formed. $\Delta g$ is the free volume energy of nucleation. $S(\theta)$ is the shape factor given by [57]

$$
S(\theta)=\frac{1}{2}(2+\cos \theta)(1-\cos \theta)^{2}
$$

where $\theta$ is the wetting angle.

The optimum embryo shape should minimize the total interfacial free energy in two abutted spherical caps with wetting angle $\theta$ [57],

$$
\cos \theta=\frac{\gamma_{\beta \beta}}{2 \gamma_{\alpha \beta}}
$$

where $\gamma_{\beta \beta}$ is the free interface energy when the connect surface $S_{\alpha \beta}$ is destroyed. The nucleation rate in cooling period is varying with temperatures according to Ref. [58].

When the acicular $\alpha$ phase is formed, the migration of the interface separating the two phases $(\alpha / \beta)$ is depending on the flux of vanadium atoms between $\alpha$ and $\beta$ phases. The corresponding flux across the $\alpha / \beta$ interface is [58],

$$
J_{v}^{i}=\frac{M \Delta \mu_{v}}{V_{m}^{2}}
$$

where $M$ is the interface mobility and $V_{\mathrm{m}}$ is the molar volume of the $\alpha$ phase. $\Delta \mu_{v}$ is given as [58],

$$
\Delta \mu_{V}=\frac{R T}{C_{\beta}^{\mathrm{eq}}}\left(C_{\beta}^{\mathrm{eq}}-C_{i}\right)
$$

If a steady state exists at the interface, the fluxes must be balanced [58],

$$
J_{V}^{i}=J_{V}^{\beta}
$$

where $J_{V}^{\beta}$ is the flux of vanadium in the interior of $\beta$ phase,

$$
J_{V}^{\beta}=\frac{M R T}{C_{\beta}^{\mathrm{eq}} V_{m}^{2}}\left(C_{\beta}^{\mathrm{eq}}-C_{i}\right)
$$

where $C_{\beta}^{\mathrm{eq}}$ is the equilibrium vanadium concentration in the $\beta$ phase.

Fortran is used to compile the program for the calculations on the microstructural changes in FSW of Ti-6Al$4 \mathrm{~V}$. Matlab is used for the further data processing and image plotting.

\section{Results and discussions}

In order to validate the microstructural evolution models on the grain growth and the phase transformation, the welding temperature curve [59] shown in Figure 4 is used in the new established models. The grain growth model is used for calculations of the volume fractions of $\alpha$ and $\beta$ phases in the welding process. The phase transformation model is further used for the simulation on the formations of the acicular $\alpha$ phase. The comparisons with experimental data [59] are shown in Figure 5. The comparisons of the two models and the experimental data can show the validities of the proposed grain growth and phase transformation models. The errors between the phase transformation model and the experimental data range from $1 \% \sim 5 \%$, which can validate the proposed models. In comparison with the grain growth model, the errors of the phase transformation model are smaller. It can be apparently seen that the decrease of the 


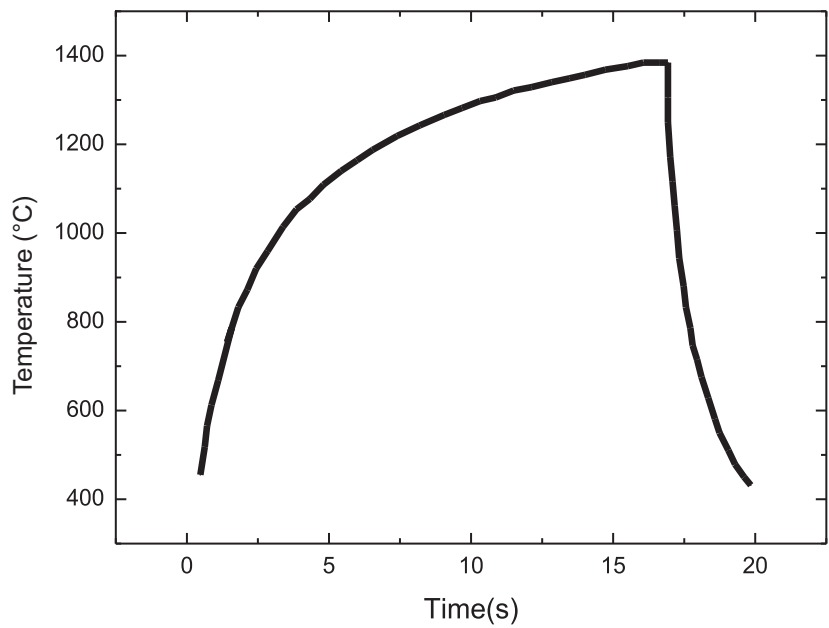

Figure 4: Temperature used in experiment [59].

temperature results in higher volume fraction of $\alpha$ phase and longer acicular $\alpha$ grains in the cooling process.

After the validation of the proposed grain growth and phase transformation models, the temperature curves calculated from the adaptive re-meshing model of FSW are used.
Adaptive re-meshing model is used to obtain the temperature histories in different welding zones, as shown in Figure 6. The accuracy for the prediction of temperatures in FSW has been validated in previous work [52]. Figures 6 (a) and (b) illustrate the temperature histories in SZ and HAZ respectively in the FSW processes and the subsequent cooling processes in different cases. The welding parameters for all cases are listed in Table 1. The temperature curve in Figure 6 (a) is selected in the middle of the welding line and the location of the point in Figure 6 (b) is $8 \mathrm{~mm}$ far away from the welding line. The welding temperature in $\mathrm{SZ}$ is much higher than HAZ, which is higher enough for recrystallization, which has been validated and observed in experiments [60, 61]. The welding temperature in HAZ can lead to coarsening of the grains. The increase of rotating speeds and the decrease of the welding speeds can lead to the increase of the maximum welding temperatures in SZ and HAZ, which has been widely observed in both experimental and numerical results $[62,63]$.

The temperature distributions perpendicular to the welding line in all 3 cases are shown in Figure 7. It shows that the maximum temperature occurs under the tool shoulder. When the maximum temperature reaches over

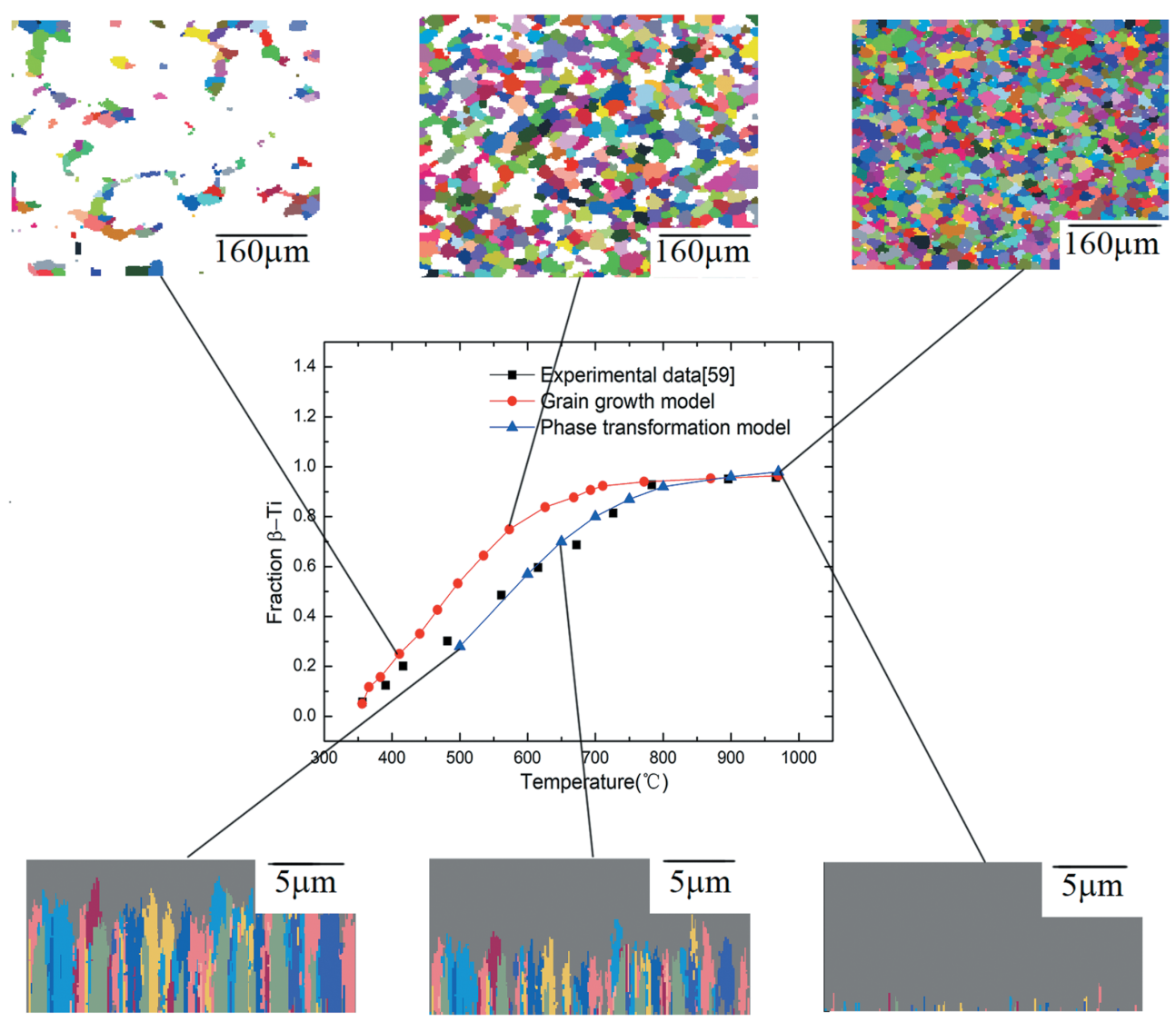

Figure 5: Variation of volume fraction of $\beta$ in SZ with time. 


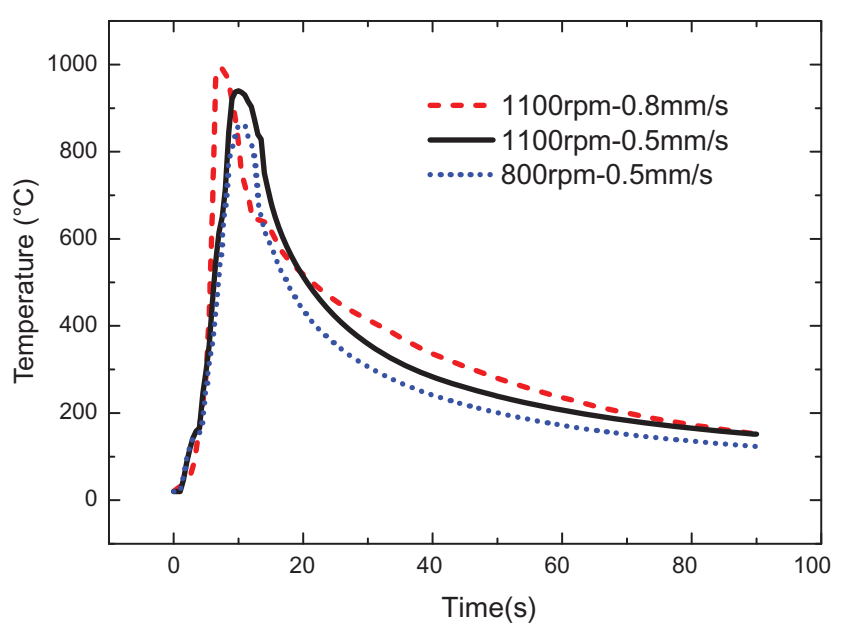

(a) SZ

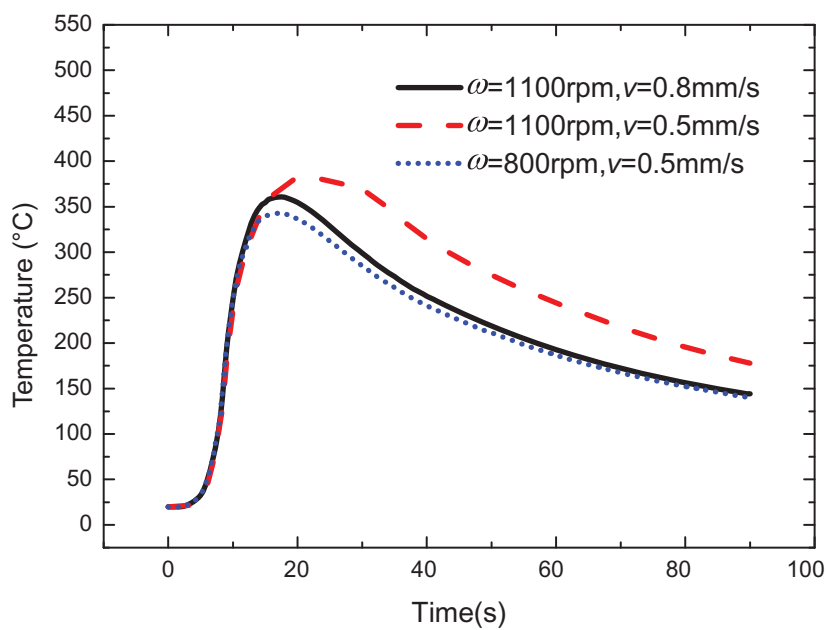

(b) HAZ

Figure 6: Temperature histories.

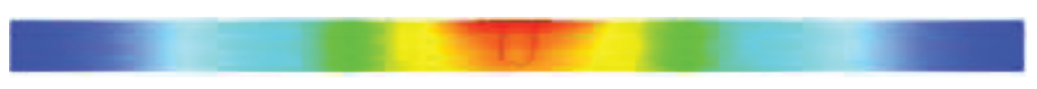

(a) $\omega=1100 \mathrm{rpm}, v=0.5 \mathrm{~mm} / \mathrm{s}$

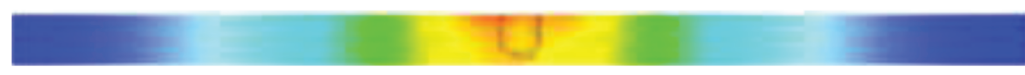

(b) $\omega=1100 \mathrm{rpm}, v=0.8 \mathrm{~mm} / \mathrm{s}$

(c) $\omega=800 \mathrm{rpm}, v=0.5 \mathrm{~mm} / \mathrm{s}$

Figure 7: Temperature distribution during the weld in different cases.

$980^{\circ} \mathrm{C}$ (e.g. $\left.v=0.5 \mathrm{~mm} / \mathrm{s}, \omega=1100 \mathrm{rpm}\right)$, all the phases can be transformed into $\beta$ phase. When the temperature drops to $600^{\circ} \mathrm{C}$, the phase transformation from $\beta$ to $\alpha$ stops [63]. With combination of the obtained temperature histories in both SZ and HAZ and the new proposed microstructural evolution model, the grain growth and the formation of acicular $\alpha$ phase can be further simulated.

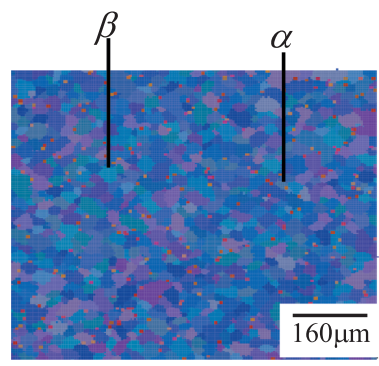

(a)MCS=29, t=16s

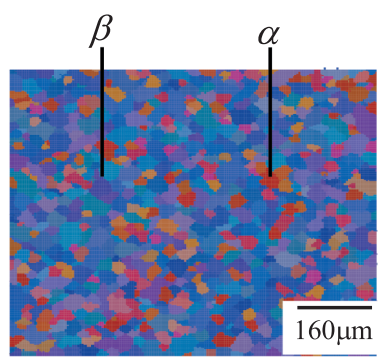

(b) $\mathrm{MCS}=60, \mathrm{t}=25 \mathrm{~s}$

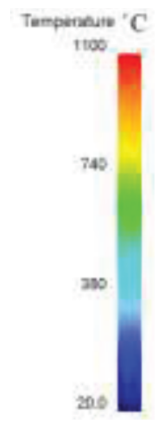

The grain growth in $1100 \mathrm{rpm}$ and $0.5 \mathrm{~mm} / \mathrm{s}$ in SZ are shown in Figure 8. In current case, the maximum welding temperature is higher than $980^{\circ} \mathrm{C}$ (as shown in Figures 6 and 7), $\alpha$ and $\beta$ phases can be transformed into $\beta$ phase before cooling. The initial grain size in HAZ is considered to be $40 \mu \mathrm{m}$ [55]. Due to the recrystallization, the grains in $\mathrm{SZ}$ are broken into finer and smaller grains which are

Figure 8: Grain growth of $\alpha / \beta$ phases in SZ in $1100 \mathrm{rpm}$ and $0.5 \mathrm{~mm} / \mathrm{s}$.

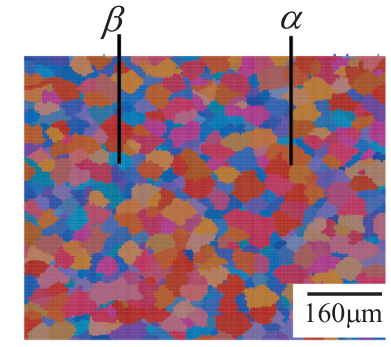

(c) $\mathrm{MCS}=98, \mathrm{t}=59 \mathrm{~s}$ 
about $4 \mu \mathrm{m}[47,49]$ by the rotation and the translation of the welding tool with mixing effects for the initial state for the grain growth. The embryos for $\alpha$ grains are generated on the boundaries of $\beta$ grains and becomes bigger in the following air cooling process. Both $\alpha$ and part of $\beta$ grains become coarsened but the grain growth rate of $\alpha$ grains is faster. The other part of $\beta$ grains can be replaced by $\alpha$ grains.

Figure 9 shows the grain growth in HAZ in $1100 \mathrm{rpm}$ and $0.5 \mathrm{~mm} / \mathrm{s}$. Due to the lower temperatures in HAZ, no phase transformation takes place and only grain coarsening occurs. In comparison with the smaller grains in SZ, the average grain size in HAZ is $138 \mu \mathrm{m}$.

The variations of the average grain sizes in both $\mathrm{SZ}$ and HAZ in all the used 3 cases are compared in Figure 10. Figure 10 shows that the grain sizes in SZ and HAZ can be increased with the increase of the rotating speed but decreased with the increase of the transverse speed. When the rotating speed is increased from $800 \mathrm{rpm}$ to $1100 \mathrm{rpm}$, the grain size in SZ can be increased from $14.5 \mu \mathrm{m}$ to $17.2 \mu \mathrm{m}$ and the grain size in
HAZ is increased from $129 \mu \mathrm{m}$ to $138 \mu \mathrm{m}$. When the transverse speed is increased from $0.5 \mathrm{~mm} / \mathrm{s}$ to $0.8 \mathrm{~mm} /$ $\mathrm{s}$, the grain size in SZ is decreased from $17.2 \mu \mathrm{m}$ to $16 \mu \mathrm{m}$ and the grain size is HAZ is also decreased from $138 \mu \mathrm{m}$ to $132 \mu \mathrm{m}$. With consideration of the temperature curves shown in Figure 6, it can be seen that higher welding temperature can lead to the increase of grain sizes in both SZ and HAZ. This phenomenon has been clearly observed in experimental tests [64], which can further validate the current proposed model. From the temperature curves, it can be also obtained that higher welding temperature in FSW means longer cooling time in air, which can lead to larger grains in both SZ and HAZ.

Figure 11 illustrates the distributions of the average grain size on the cross sections after welding in different welding conditions. Due to the recrystallization in SZ, the grain size in SZ is much smaller than HAZ, which is caused by the stirring effect on the initial grains and the new nuclei generated in SZ. There is no obvious thermalmechanical affected zone observed in this figure, which can be also confirmed by experiments [65]. The grains

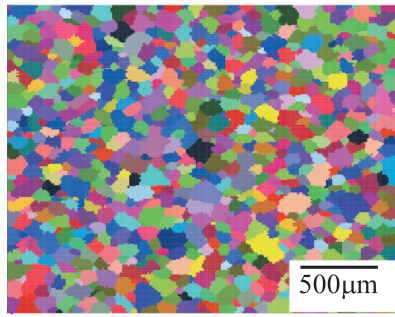

(a) $\mathrm{MCS}=29$

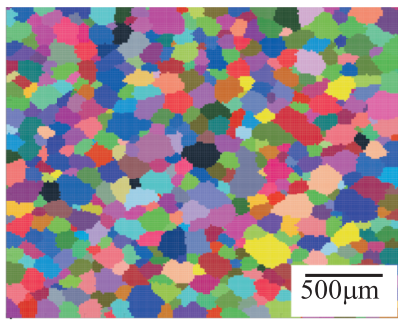

(b) $\mathrm{MCS}=60$

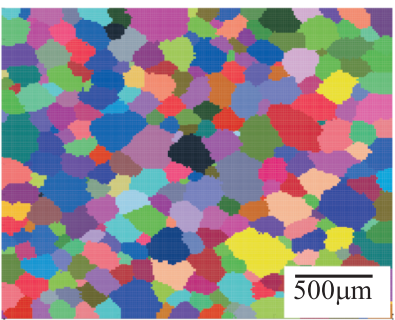

(c) $\mathrm{MCS}=98$

Figure 9: Grain growth of $\alpha / \beta$ phases in HAZ in $1100 \mathrm{rpm}$ and $0.5 \mathrm{~mm} / \mathrm{s}$.

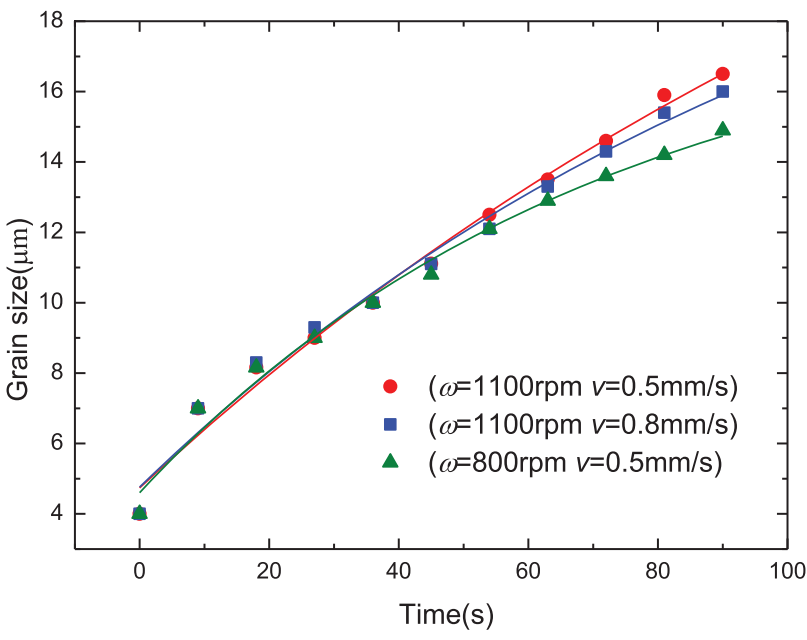

(a)SZ

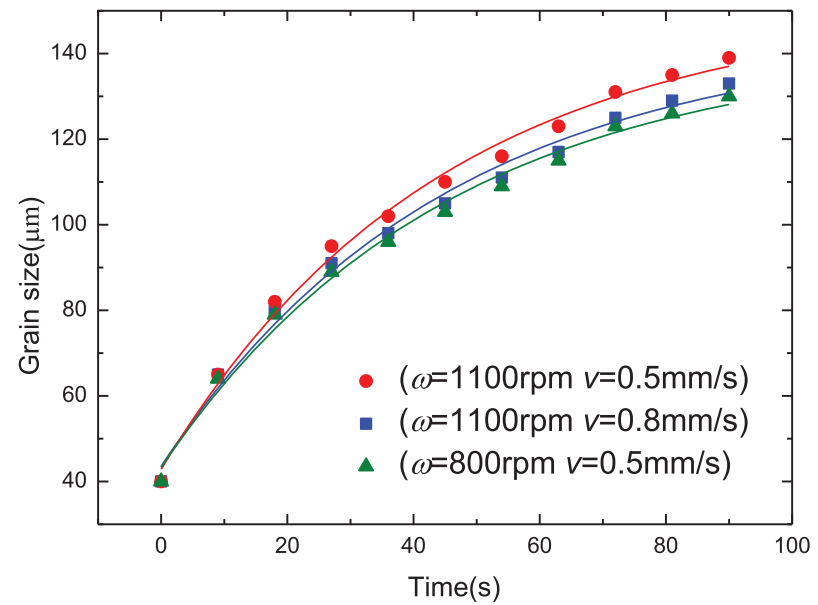

(b)HAZ

Figure 10: Variations of grain sizes with time in different welding conditions. 


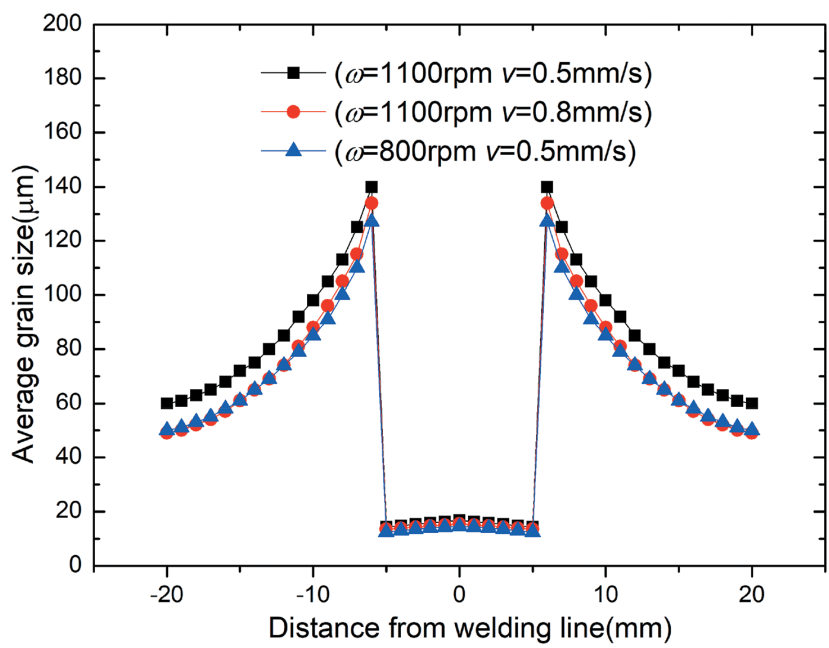

Figure 11: Distribution of average grain size in welding zones. near the outer border of the HAZ gradually become similar to the grains in base metal.

The morphologies of $\alpha$ and $\beta$ phases during the cooling progresses in different welding conditions are shown in Figure 12. The $\alpha$ phase (white zone) and $\beta$ phase in the process of the air cooling are taken at $850^{\circ} \mathrm{C}, 750^{\circ} \mathrm{C}$ and $600^{\circ} \mathrm{C}$. It is obvious that $\alpha$ grains occur on the boundaries of $\beta$ grains and both of them can be increased in the cooling process in FSW. Due to the higher cooling rate above $600^{\circ} \mathrm{C}$, the transformation from $\beta$ phase to $\alpha$ phase is incomplete in all the studied cases.

The volume fractions of $\alpha$ phase in different welding conditions are shown in Figure 13. It is shown that the volume fraction of $\alpha$ phase can reach $81.3 \%$ in $1100 \mathrm{rpm}$ and $0.5 \mathrm{~mm} / \mathrm{s}$ and $71.1 \%$ in $1100 \mathrm{rpm}$ and $0.8 \mathrm{~mm} / \mathrm{s}$ when the temperature is cooled down to $600^{\circ} \mathrm{C}$.

\section{$850^{\circ} \mathrm{C}$}

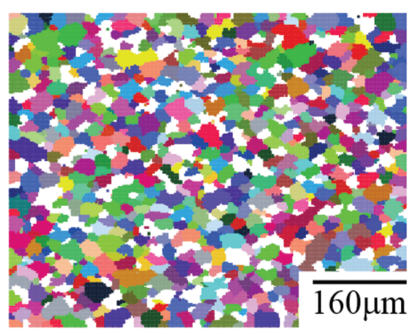

$750^{\circ} \mathrm{C}$

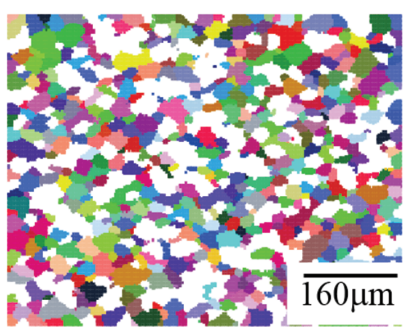

$600^{\circ} \mathrm{C}$

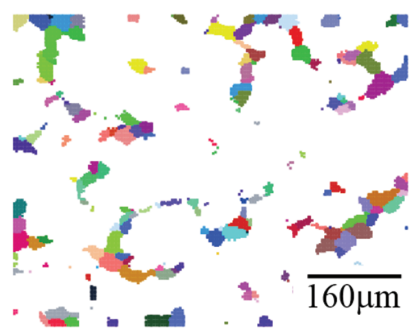

(a) $\omega=1100 \mathrm{rpm}, v=0.5 \mathrm{~mm} / \mathrm{s}$
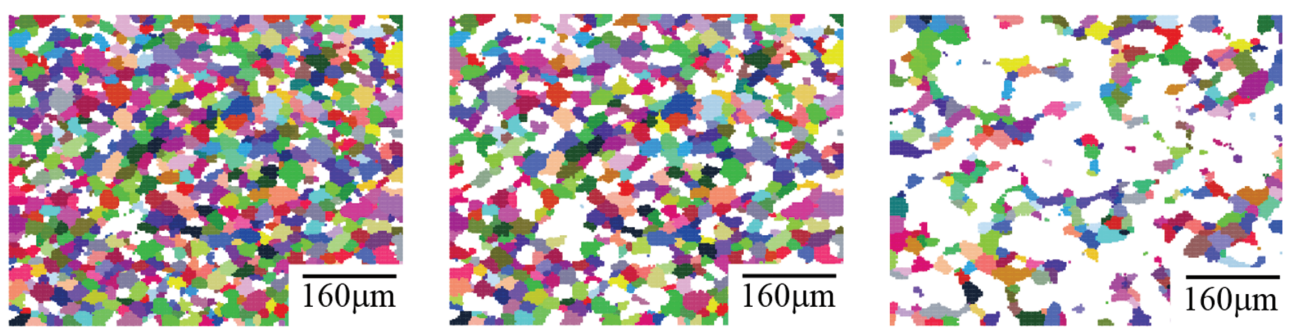

(b) $\omega=1100 \mathrm{rpm}, v=0.8 \mathrm{~mm} / \mathrm{s}$
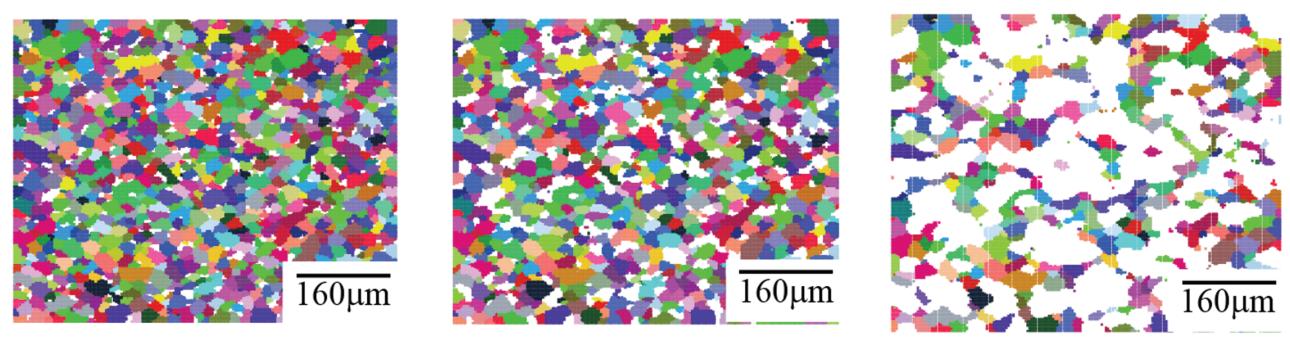

(c) $\omega=800 \mathrm{rpm}, v=0.5 \mathrm{~mm} / \mathrm{s}$

Figure 12: $\alpha$ and $\beta$ phases during the cooling progresses in different welding conditions. 


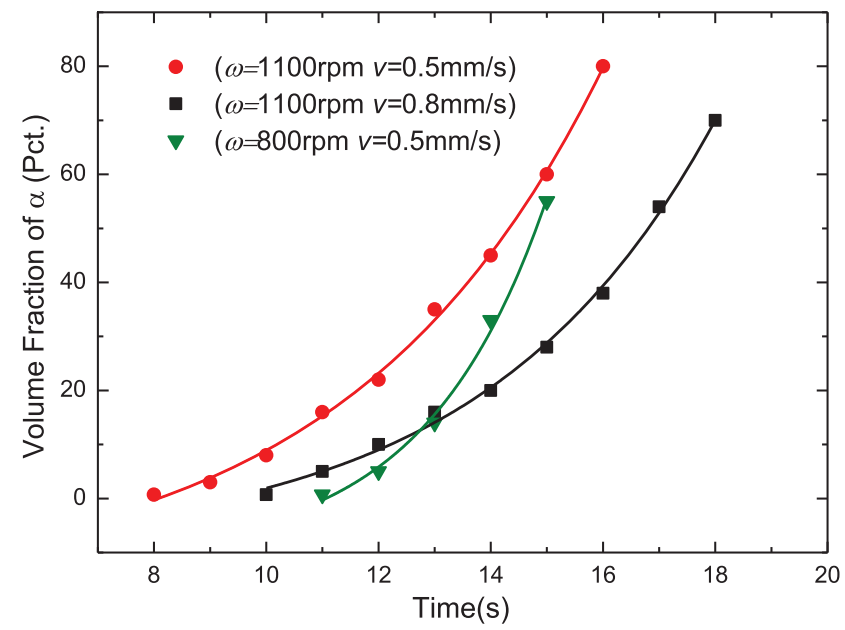

Figure 13: Predicted volume fractions of $\alpha$ in SZ.
However, the $\alpha$ phase fraction in $800 \mathrm{rpm}$ and $0.5 \mathrm{~mm} / \mathrm{s}$ is only $54.0 \%$. This is due to the fact that the maximum welding temperature in this case is the lowest and the cooling rate is the highest above $600^{\circ} \mathrm{C}$. The volume fraction of $\alpha$ phase is significantly determined by both welding temperature and cooling rate. With the increase of the rotational speed, the volume friction of $\alpha$ phase gets increased in SZ. With the decrease of the translational speed, the volume fraction of $\alpha$ phase also gets increased. This phenomenon observed in this numerical model is fitted well with the experimental observations [66].

In $\mathrm{SZ}$, a $300 \times 150$ lattice system $(20 \mu \mathrm{m} \times 10 \mu \mathrm{m})$ is used to model the formation of acicular $\alpha$ phase inside one grain in different temperatures $\left(750^{\circ} \mathrm{C}\right.$ and $\left.600^{\circ} \mathrm{C}\right)$, as shown in Figures 14 and 15. The variations of the

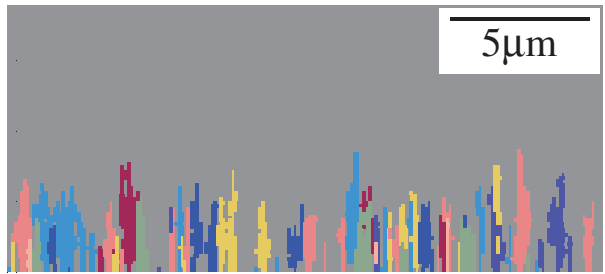

(a) $\omega=1100 \mathrm{rpm}, v=0.5 \mathrm{~mm} / \mathrm{s}$

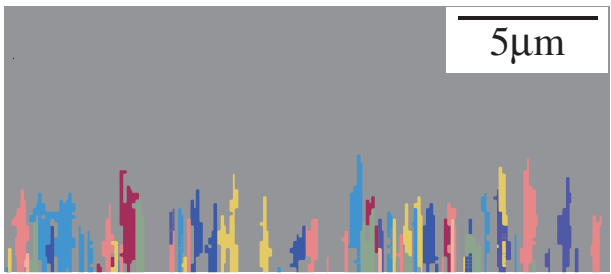

(b) $\omega=1100 \mathrm{rpm}, v=0.8 \mathrm{~mm} / \mathrm{s}$

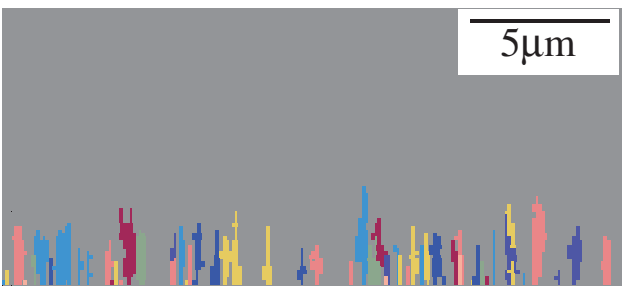

(c) $\omega=800 \mathrm{rpm}, v=0.5 \mathrm{~mm} / \mathrm{s}$

Figure 14: Formation of acicular $\alpha$ phase morphology in $750^{\circ} \mathrm{C}$ in different welding conditions.

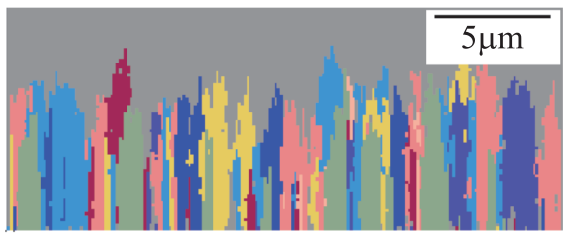

(a) $\omega=1100 \mathrm{rpm}, v=0.5 \mathrm{~mm} / \mathrm{s}$

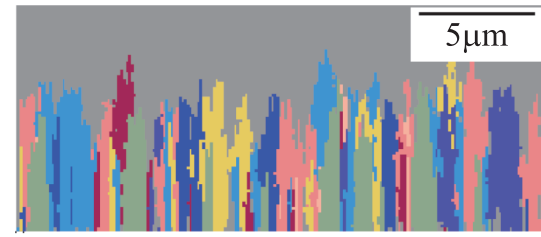

(b) $\omega=1100 \mathrm{rpm}, v=0.8 \mathrm{~mm} / \mathrm{s}$

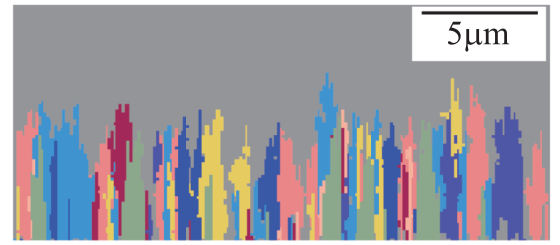

(c) $\omega=800 \mathrm{rpm}, v=0.5 \mathrm{~mm} / \mathrm{s}$

Figure 15: Formation of acicular $\alpha$ phase morphology in $600^{\circ} \mathrm{C}$ in different welding conditions. 
average length of acicular $\alpha$ phase with welding temperatures in different welding conditions are further summarized in Figure 16. The length of acicular $\alpha$ grain is strongly dependent on the maximum welding temperature and the corresponding cooling rate during the FSW process. Actually, higher cooling rate can limit the time for growth of $\alpha$ grain. This is the reason that the length of acicular $\alpha$ grain can be decreased with the increase of the transverse speed. For the case in 800 $\mathrm{rpm}$ and $0.5 \mathrm{~mm} / \mathrm{s}$, the welding temperature is the lowest and the cooling rate is the highest. This is the reason for the formation of the smallest $\alpha$ grain in this case. With the decrease of welding temperature in the FSW process, the average length of acicular $\alpha$ grain is gradually increased.

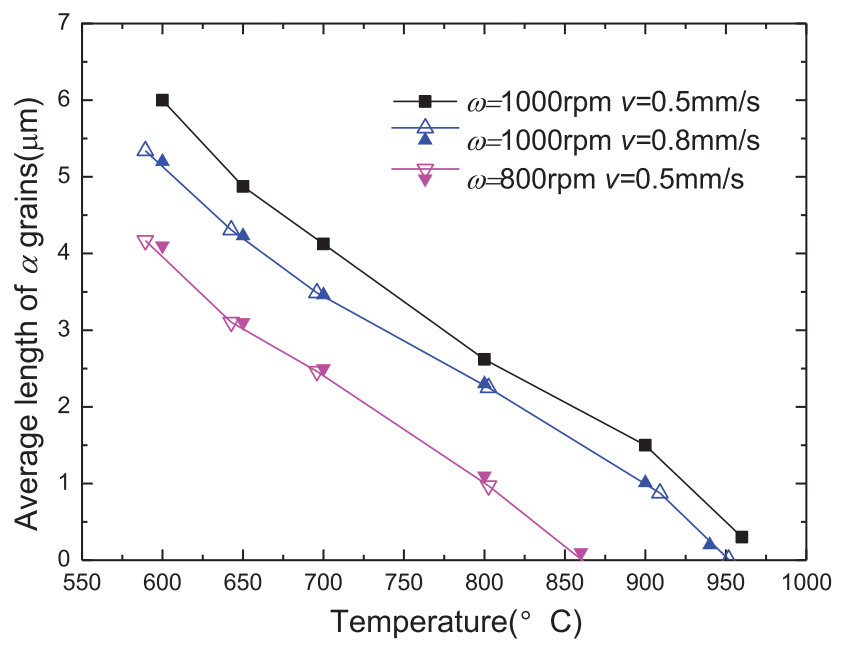

Figure 16: The average length of acicular $\alpha$ grains in different welding conditions.

\section{Conclusions}

A Monte Carlo model for grain growth in FSW of duplex Ti alloy is newly proposed. A phase transformation model is further established to simulate the formation of the acicular $\alpha$ grain. Comparisons with the experimental data and phenomena show the validity of the proposed models. The main observations and results are summarized as follows,

(1) The volume fraction of $\alpha$ phase can be predicted by both the proposed grain growth model in grain cluster scale and the phase transformation model in one grain scale. Comparison with experimental data shows that the results from the phase transformation model in one grain scale is more accurate.
(2) The grain growth and the length of the acicular $\alpha$ grain are dependent on both the maximum welding temperature and the corresponding cooling rate. Lower rotational speed or higher transverse speed can lead to lower welding temperature, which can lead to smaller grain sizes in SZ.

(3) Due to the recrystallization in SZ, the grain size in SZ is much smaller than HAZ, which is caused by the stirring effect on the initial grains and the new nuclei generated in SZ.

(4) Due to the higher cooling rate above $600^{\circ} \mathrm{C}$, the transformation from $\beta$ phase to $\alpha$ phase is incomplete in FSW of Ti-6Al-4V.

Funding: This work is financially supported by the National Natural Science Foundation of China (Funder Id: $10.13039 / 501100001809$, No. 11572074) and the Fundamental Research Funds for the Central Universities.

Conflict of interest: The authors declare that they have no conflict of interest.

\section{References}

[1] R.S. Mishra and Z.Y. Ma, Friction stir welding and processing, Mater. Sci. Eng., R, 50 (2005) 1-78.

[2] D. Lohwasser and Z. Chen, Friction Stir Welding: From Basics to Applications, Cambridge: Woodhead Publishing Limited (2010).

[3] P.L. Threadgill, A.J. Leonard, H.R. Shercliff and P.J. Withers, Friction stir welding of aluminium alloys, Int. Mater. Rev., 54 (2009) 49-93.

[4] W.D.P. Brassington and P.A. Colegrove, Alternative friction stir welding technology for titanium-6Al-4V propellant tanks within the space industry, Sci. Technol. Weld. Joining, 22 (2017) 300318.

[5] M.M.Z. Ahmed, S. Ataya, M.M.E.S. Selema, H.R. Ammar and E. Ahmed, Friction stir welding of similar and dissimilar AA7075 and AA5083, J. Mater. Process. Technol., 242 (2017) 77-91.

[6] S. Gao, C.S. Wu and G.K. Padhy, Material flow, microstructure and mechanical properties of friction stir welded AA 2024-T3 enhanced by ultrasonic vibrations, J. Manuf. Process., 30 (2017) 385-395.

[7] L. Long, G.Q. Chen, S. Zhang, T. Liu and Q.Y. Shi, Finiteelement analysis of the tool tilt angle effect on the formation of friction stir welds, J. Manuf. Process., 30 (2017) 562-569.

[8] J.M. Tang and Y.F. Shen, Numerical simulation and experimental investigation of friction stir lap welding between aluminum alloys AA2024 and AA7075, J. Alloys. Compd., 666 (2016) 493-500.

[9] S.D. Ji, Z.P. Yang, Q. Wen, Y.M. Yue and L.G. Zhang, Effect of trailing intensive cooling on residual stress and welding distortion of friction stir welded 2060 al-li alloy, High Temp. Mater. Processes, 37 (2018) 397-403. 
[10] W.D. Wang, D. Deng, Z.T. Mao, Y.G. Tong and Y. Ran, Influence of tool rotation rates on temperature profiles and mechanical properties of friction stir welded AZ31 magnesium alloy, Int. J. Adv. Manuf. Technol., 88 (2017) 2191-2200.

[11] S. Mironov, T. Onuma, Y.S. Sato, S. Yoneyama and H. Kokawa, Tensile behavior of friction-stir welded AZ31 magnesium alloy, Mater. Sci. Eng., A, 679 (2017) 272-281.

[12] R.Z. Xu, D.R. Ni, Q. Yang, C.Z. Liu and Z.Y. Ma, Influence of Zn interlayer addition on microstructure and mechanical properties of friction stir welded AZ31 Mg alloy, J. Mater. Sci., 50 (2015) 4160-4173.

[13] L.H. Wu, P. Xue, B.L. Xiao and Z.Y. Ma, Achieving superior lowtemperature superplasticity for lamellar microstructure in nugget of a friction stir welded Ti-6Al-4V joint, Scr. Mater., 122 (2016) 26-30.

[14] S. Yoon, R. Ueji and H. Fujii, Microstructure and texture distribution of Ti-6Al-4V alloy joints friction stir welded below beta-transus temperature, J. Mater. Process. Technol., 229 (2016) 390-397.

[15] M. Muzvidziwa, M. Okazaki, K. Suzuki and S. Hirano, Role of microstructure on the fatigue crack propagation behavior of a friction stir welded Ti-6Al-4V, Mater. Sci. Eng., A, 652 (2016) 59-68.

[16] F.C. Liu and T.W. Nelson, In-situ material flow pattern around probe during friction stir welding of austenitic stainless steel, Mater. Des., 110 (2016) 354-364.

[17] T.N. Baker and N.A. McPherson, Properties and microstructure of double-sided friction stir-welded microalloyed steel, Mater. Sci. Technol., 33 (2017) 234-243.

[18] A.P. Reynolds, W. Tang, T. Gnaupel-Herold and H. Prask, Structure, properties, and residual stress of $304 \mathrm{~L}$ stainless steel friction stir welds, Scr. Mater., 48 (2003) 1289-1294.

[19] Y.X. Huang, X.C. Meng, Y.M. Xie, L. Wan, Z.L. Lv, J. Cao and J.C. Feng, Friction stir welding/processing of polymers and polymer matrix composites, Compos. Part A: Appl. Sci. Manuf., 105 (2018) 235-257.

[20] Y.X. Huang, X.C. Meng, Y.M. Xie, J.C. Li and L. Wan, Joining of carbon fiber reinforced thermoplastic and metal via friction stir welding with co-controlling shape and performance, Compos. Part A: Appl. Sci. Manuf., 112 (2018) 328-336.

[21] H.J. Liu, J.J. Shen, S. Xie, Y.X. Huang, F. Cui, C. Liu and L.Y. Kuang, Weld appearance and microstructural characteristics of friction stir butt barrier welded joints of aluminium alloy to copper, Sci. Technol. Weld. Joining, 17 (2012) 104-110.

[22] Y.X. Huang, Y.M. Xie, X.C. Meng, Z.L. Lv and J. Cao, Numerical design of high depth-to-width ratio friction stir welding, J. Mater. Process. Technol., 252 (2018) 233-241.

[23] Z. Zhang and H.W. Zhang, Numerical studies on controlling of process parameters in friction stir welding, J. Mater. Process. Technol., 209 (2009) 241-270.

[24] Z. Zhang, Q. Wu and H.W. Zhang, Numerical studies of effect of tool sizes and pin shapes on friction stir welding of AA2024-T3, Trans. Nonferrous Met. Soc. China, 24 (2014) 3293-3301.

[25] A. Arora, A. De and T. DebRoy, Toward optimum friction stir welding tool shoulder diameter, Scr. Mater., 64 (2011) 9-12.

[26] T.R. McNelley, S. Swaminathan and J.Q. Su, Recrystallization mechanisms during friction stir welding/processing of aluminum alloys, Scr. Mater., 58 (2008) 349-354.
[27] L.E. Murr, G. Liu and J.C. McClure, Dynamic recrystallization in friction-stir welding of aluminium alloy 1100 , J. Mater. Sci. Lett., 16 (1997) 1801-1803.

[28] Z. Zhang and J.T. Chen, Computational investigations on reliable finite element based thermo-mechanical coupled simulations of friction stir welding, Int. J. Adv. Manuf. Technol., 60 (2014) 959-975.

[29] Z. Zhang, J.T. Chen, Z.W. Zhang and H.W. Zhang, Coupled thermo-mechanical model based comparison of friction stir welding processes of AA2024-T3 in different thicknesses, J. Mater. Sci., 46 (2011) 5815-5821.

[30] Z. Zhang and H.W. Zhang, Numerical studies on the effect of transverse speed in friction stir welding, Mater. Des., 30 (2009) 900-907.

[31] R. Nandan, G.G. Roy, T.J. Lienert and T. Debroy, Three-dimensional heat and material flow during friction stir welding of mild steel, Acta Mater., 55 (2007) 883-895.

[32] Z. Zhang and Q. Wu, Analytical and numerical studies of fatigue stresses in friction stir welding, Int. J. Adv. Manuf. Technol., 78 (2015) 1371-1380.

[33] Z. Zhang, Q. Wu and H.W. Zhang, Prediction of fatigue life of welding tool in friction stir welding of AA6061-T6, Int. J. Adv. Manuf. Technol., 86 (2016) 3407-3415.

[34] H. Schmidt and J. Hattel, A local model for the thermomechanical conditions in friction stir welding, Modell. Simul. Mater. Sci. Eng., 13 (2005) 77-93.

[35] G. Buffa, J. Hua, R. Shivpuri and L. Fratini, A continuum based FEM model for friction stir welding - model development, Mater. Sci. Eng., A, 419 (2006) 389-396.

[36] X.X. Zhang, D. Wang, B.L. Xiao, H. Andrae, W.M. Gan, M. Hofmann and Z.Y. Ma, Enhanced multiscale modeling of macroscopic and microscopic residual stresses evolution during multi-thermo-mechanical processes, Mater. Des., 115 (2017) 364-378.

[37] X.K. Zhu and Y.J. Chao, Numerical simulation of transient temperature and residual stresses in friction stir welding of $304 \mathrm{~L}$ stainless steel, J. Mater. Process. Technol., 146 (2004) 263272.

[38] V.S. Gadakh, A. Kumar and G.J.V. Patil, Analytical modeling of the friction stir welding process using different pin profiles, Weld. J., 94 (2015) 115S-124S.

[39] P.A. Colegrove, H.R. Shercliff and R. Zettler, Model for predicting heat generation and temperature in friction stir welding from the material properties, Sci. Technol. Weld. Joining, 12 (2007) 284-297.

[40] Z. Zhang and H.W. Zhang, Solid mechanics-based Eulerian model of friction stir welding, Int. J. Adv. Manuf. Technol., 72 (2014) 1647-1653.

[41] Z.W. Zhang, Z. Zhang and H.W. Zhang, Numerical investigations of size effects on residual states of friction stir weld, Proc. IMechE Part B: J. Eng. Manuf., 228 (2014) 572-581.

[42] Z. Zhang and Q. Wu, Numerical studies of tool diameter on strain rates, temperature rises and grain sizes in friction stir welding, J. Mech. Sci. Technol., 29 (2015) 4121-4128.

[43] H.S. Arora, H. Singh and B.K. Dhindaw, Numerical simulation of temperature distribution using finite difference equations and estimation of the grain size during friction stir processing, Mater. Sci. Eng., A, 543 (2012) 231-242.

[44] Z.H. Zhang, W.Y. Li, J.L. Li and Y.J. Chao, Effective predictions of ultimate tensile strength, peak temperature and grain size of 
friction stir welded AA2024 alloy joints, Int. J. Adv. Manuf. Technol., 73 (2014) 1213-1218.

[45] S.R. Valvi, A. Krishnan and S. Das, Narayanan RG Prediction of microstructural features and forming of friction stir welded sheets using cellular automata finite element (CAFE) approach, Int. J. Mater. Form., 9 (2016) 115-129.

[46] K.J. Song, Z.B. Dong, K. Fang, Z.H. Zhan and Y.H. Wei, Cellular automaton modelling of dynamic recrystallisation microstructure evolution during friction stir welding of titanium alloy, Mater. Sci. Technol., 30 (2014) 700-711.

[47] Z. Zhang, Q. Wu, M. Grujicic and Z.Y. Wan, Monte Carlo simulation of grain growth and welding zones in friction stir welding of AA6082-T6, J. Mater. Sci., 51 (2016) 1882-1895.

[48] M. Grujicic, S. Ramaswami, J.S. Snipes, V. Avuthu, R. Galgalikar and Z. Zhang, Prediction of the grain-microstructure evolution within a Friction Stir Welding (FSW) joint via the use of the Monte Carlo simulation method, J Mater Eng Perform, 24 (2015) 3471-3486.

[49] Q. Wu and Z. Zhang, Precipitation induced grain growth simulation of friction stir welded AA6082-T6, J Mater Eng Perform, 26 (2017) 2179-2189.

[50] Q. Zhang, J. Chen, L.L. Wang, H. Tan, X. Lin and W.D. Huang, Solidification microstructure of laser additive manufactured Ti-6Al-2Zr-2Sn-3Mo-1.5Cr-2Nb titanium alloy, J. Mater. Sci. Technol., 32 (2016) 381-386.

[51] Z. Zhang and H.W. Zhang, Numerical studies of pre-heating time effect on temperature and material behaviors in friction stir welding process, Sci. Technol. Weld. Joining, 12 (2007) 436-448.

[52] Z. Zhang and Z.Y. Wan, Predictions of tool forces in friction stir welding of AZ91 magnesium alloy, Sci. Technol. Weld. Joining, 17 (2012) 495-500.

[53] O.C. Zienkiewicz and J.Z. Zhu, A simple error estimator and adaptive procedure for practical engineering analysis, Int. J. Numer. Meth. Eng., 24 (1987) 337-357.

[54] J. Gao and R.G. Thompson, Real time-temperature models for Monte Carlo simulations of normal grain growth, Acta Mater., 44 (11) (1996) 4565-4570.
[55] A.R.A. Dezfoli and W.S. Hwang, Monte Carlo simulation of Ti-6Al-4V grain growth during fast heat treatment, $\mathrm{Cmc}, 49$ (1) (2015) 1-11.

[56] S.L. Semiatin, J.C. Soper and I.M. Sukonnik, Grain growth in a conventional titanium alloy during rapid, continuous heat treatment, Scr. Metall. Mater., 30 (7) (1994) 951-955.

[57] I. Katzarov, S. Malinov and W. Sha, Finite element modeling of the morphology of $\beta$ to $\alpha$ phase transformation in Ti-6Al-4V alloy, Metall. Mater. Trans. A, 33 (4) (2002) 1027-1040.

[58] W. Sha and S. Malinov, Titanium Alloys: Modelling of Microstructure, Properties and Applications, Cambridge: Woodhead publishing limited (2009).

[59] J.W. Elmer, T.A. Palmer, S.S. Babu, W. Zhang and T. DebRoy, Phase transformation dynamics during welding of Ti-6Al-4V, J. Appl. Phys., 95 (12) (2004) 8327-8339.

[60] R. Dąbrowski, The kinetics of phase transformations during continuous cooling of Ti6Al4V alloy from the diphase $\alpha+\beta$ range, Arch. Metall. Mater., 56 (2) (2011) 217-221.

[61] J.D.C. Teixeira, B. Appolaire, E. Aeby-Gautier, S. Denis and F. Bruneseaux, Modeling of the effect of the $\beta$ phase deformation on the $\alpha$ phase precipitation in near- $\beta$ titanium alloys, Acta Mater., 54 (16) (2006) 4261-4271.

[62] S.A. Khodir, T. Shibayanagi and M. Naka, Microstructure and mechanical properties of friction stir welded AA2024-T3 aluminum alloy, Mater. Trans., 47 (1) (2006) 185-193.

[63] G. Buffa, A. Ducato and L. Fratini, FEM based prediction of phase transformations during friction stir welding of Ti6Al4V titanium alloy, Mater. Sci. Eng.: A, 581 (2013) 56-65.

[64] Y. Zhang, Y.S. Sato, H. Kokawa, S.H.C. Park and S. Hirano, Microstructural characteristics and mechanical properties of Ti-6Al-4V friction stir welds, Mater. Sci. Eng.: A, 485 (1) (2008) 448-455.

[65] S. Mironov, Y. Zhang, Y.S. Sato and H. Kokawa, Development of grain structure in $\beta$-phase field during friction stir welding of Ti-6Al-4V alloy, Scr. Mater., 59 (1) (2008) 27-30.

[66] K.J. Song, Y.H. Wei, Z.B. Dong, X.H. Zhan, W.J. Zheng and K. Fang, Numerical simulation of $\beta$ to $\alpha$ phase transformation in heat affected zone during welding of TA15 alloy, Comput. Mater. Sci., 72 (2) (2013) 93-100. 